\title{
A phytomass-inspired carbon and its importance as an antibacterial agent against human pathogens
}

\author{
N. Anvarsha and P. Kalyani*
}

\begin{abstract}
Background: Imprudent use of antimicrobial drugs has resulted in the microbial resistance among the known microbes and hence we foresee a pressing need towards the development of novel, low-cost, and high potent antimicrobials which should be munificent by nature. In the pursuit of the above, phosphoric acid activated lowcost carbon was produced from a renewable phytomass precursor viz., leaves of Vitex negundo L. plant and explored for its antibacterial efficacy against four human pathogens viz., S. aureus, S. pyogenes (Gram-positive bacteria), and E. coli, P. aeruginosa (Gram-negative bacteria) by adopting well diffusion method. Carbon yield, burnoff, phase purity, elemental composition, particle morphology, and surface functionalities have been studied by ultimate elemental analysis, X-ray diffractometry, elemental analysis, scanning electron microscopy, and Fourier transform infrared spectrophotometry respectively. Minimal inhibition concentration (MIC) was also followed. Plausible mechanism of killing the pathogens by the above activated carbon was also provided.

Results: Vitex negundo leaves derived activated carbon (VNLAC) was found to contain large number of O-, S- and $\mathrm{N}$-containing surface groups which are supposedly responsible for bestowing antibacterial properties to the carbon derived from Vitex negundo leaves. It has emerged as a potential antibacterial agent for many Gram-negative as well as Gram-positive bacteria. The inhibition zone of mean diameters ranged from 9 to $25 \mathrm{~mm}$ against all the pathogens was significantly $(p<0.05)$ less than that of the control viz., ciprofloxacin. Thus, the fundamental experimental results may extend the limits of carbon sources but also the conventional idea of obtaining active carbon to apply in technologies where carbon is inevitable.

Conclusion: The work not only demonstrates the promising potential of VNLAC as an efficient antibacterial agent but also presents a feasible mechanism of action of removing pathogens. Vitex negundo-derived carbon may become a cheap substitute for cost-prohibitive drugs. The findings of the work illustrate an easy choice as an antibacterial for topical application at infected sites.
\end{abstract}

Keywords: Phytomass, Activated carbon, Pathogens, Antibacterial efficacy, Vitex negundo L

\section{Background}

It is well known that antimicrobials may act like killing agents or impede the growth of microorganisms. On the one hand, due to the extraordinary recombination capability of the microorganisms, the genetic materials undergo rapid mutagenic transformations that hinder

*Correspondence: kalyani_1973@yahoo.com

Department of Chemistry, DDE, Madurai Kamaraj University, Madurai, Tamil Nadu, India

Springer Open metabolic processes such as cell wall formation, synthesis and transcription of proteins, thus leading to the development of resistance against the known antimicrobials or antibacterials in the case of bacteria. On the other hand, recent unwise use of antibiotics has also resulted in the multitude of pathogens to develop resistance to the commonly employed antimicrobials. Therefore, pollution due to microbes is becoming one of the major threats related to environmental sanitation 
and human health ultimately. As a consequence, there arises a compelling and dire need for the research and development of novel and high potential antimicrobials which should be benevolent by nature.

Now turning to the alternatives available for the above subject, recent literature has shown that nanoparticles based on carbon nanotubes, fullerenes, and graphene oxide possess appreciable antimicrobial activity against various strains [1]. Of late, antimicrobial activities of carbon-based nanostructures are being interestingly investigated owing to their high surface to volume ratio, large inner volume, and for other unique physical and chemical properties. Therefore, technological developments towards the design and synthesis of carbon-based antimicrobials that too from waste biomass that will reduce microbial resistance and infection burden have zeroed-in recently. Falling in this line, the present work explores the prospects of utilizing zero-cost leaf biomass of Vitex negundo L. plant for deriving activated carbon for evaluating its antibacterial properties.

Generally decayed or decaying plant biomass poses eco-pollution as its water content, sugar, mineral, and proteins would favor exponential growth of microorganisms. Also, a lot of microorganisms breed before the biomass could get decomposed, eventually bringing out rotten smell thereby polluting the environment. Generally, decayed or decaying plant biomass pose environmental pollution as its sugar, mineral, protein contents, and water retention nature creates favorable conditions for proliferation of microorganisms.

Phytochemical constituents of medicinal plants have been considered to be a basic requirement in the discovery of potential medicines and remedies for various diseases in Ayurvedic and Nutraceutical research. Medicinal properties of any plant depend on the type of phyto constituents and nutritive elements as well as minerals. Medicinal plants are effective against various health problems due to their pharmacological efficacy which depends on their elemental concentrations [2]. Speaking about Vitex negundo, only medicinal properties is more frequently researched. The whole plant is traditionally important because it has many therapeutic values. It has been reported to possess potential pharmacological properties like antiinflammatory, antirheumatic, and antibiotic, hepato protective, antioxidant, anticonvulsant, oxidative stress, snake venom neutralization, and antiallergic activities [3]. The leaves of Vitex Negundo is used to treat sprain, headache, abdominal pain, tooth ache, asthma, cough, fever, boils, wounds, and ulcers due to its antiseptic, astringent, antiinflammatory, and antipyretic nature [4]. Thus, it can be seen that Vitex negundo plant has intense medicinal values and literature is also enormous. Hitherto, research is being focused only on the phytochemical composition and medicinal values of the plant Vitex negundo. However, one or two reports on activated carbon derived from Vitex negundo bark, stem, and flowers are only available [5].

Thus, it is apparent that the phytomass (plant biomass) wastes which may not have economic benefits may wisely be utilized by transforming zero-cost phytomass into activated carbon, which doubles up its worth by minimizing the waste management cost and by appreciably providing inexpensive alternative to the existing high priced commercial functional carbons. Thus, plant wastes from multiple sources present cost free and renewable carbon resource for numerous applications such as in biomedical and pharmaceutical fields as antibacterial agent.

The study of natural compounds containing sulphur and nitrogen is interesting because of their significant antibacterial, antifungal, and anticancer activity [6]. It can be shown later in this article that the biomassderived activated carbon too has sulphur and nitrogen (in addition to carbon, hydrogen, and oxygen) which are present as organic functional moieties in its structure to explain the observed effect against the pathogens. During the past 5 years, not many articles have appeared in the literature describing the biological activities using biomass-derived activated carbon alone. But to cite a few examples, using groundnut shell, Yallappa et al. [7] have done a pioneering work in the regard above. Lakshmi et al. have elaborately reviewed activated carbon nanoparticles from biowaste as a new generation antimicrobial agents [8]. It is interesting to know that the kitchen soot was once applied as an antimicrobial and called "old woman's remedy [9]. In that sense, Sheena et al. [9] have reported antimicrobial activity of carbon nanoparticles isolated from natural sources against pathogenic Gram-negative and Gram-positive bacteria. Sekaran et al. [10] have reported the preparation of mesoporous-activated carbon from rice husk by precarbonization at $400{ }^{\circ} \mathrm{C}$, chemical activation using phosphoric acid at various temperatures and have immobilized Bacillus sp. in the mesoporous-activated carbon for the degradation of sulphonated phenolic compounds in wastewater. Karthik et al. [11] have prepared activated carbon from Tribulus terrestris and have shown activity against E. coli, B. subtilis, S. aureus, and $K$. pneumoniae. Shamsi et al. [12] have reported a clear zone of inhibition of carbon nanoparticles obtained from sandal wood bark against B. cereus, E. coli, C. violeceum, and $P$. notatum due to these nanoparticles. Dheepan et al. [13] have reported in vitro evaluation of antibacterial efficacy using passiflora foetida-activated carbon against a score of pathogens. All these reports conclude that carbon materials produced from biomass still has enormous potential for acting against various strains of 
bacteria and that extended research is needed for a commercial success in the near future. Therefore, it is definite that the research outcome will be a welcoming route for producing zero-cost phytomass-derived cheap and affordable carbon materials possessing favorable characteristics for the intended applications.

The present research paper accordingly covers the preparation of activated carbon from natural and green source namely the leaves of $V$. negundo plant, the zerocost phytomass and the evaluation of antimicrobial activity against selected human bacterial pathogens like $S$. aureus, S. pyogenes (Gram-positive type), and E. coli, P. aeruginosa (Gram-negative type). It further provides an ideal method for the utilization of $V$. negundo plant for producing low-cost and multifunctional-activated carbon which can be produced in bulk. This work is an evidence of taking wastes-making products-turning them in to resources (circular economy), the opposite of the current setup of seizing resources-making products-turning them to wastes (linear economy).

\section{Methods}

The raw material used for preparing biocarbon was the leaf biomass of Vitex negundo L. ( $V$. negundo) plant which is obviously economical, abundant and easily available. Pathogens selected for the present investigation are S. aureus, S. pyogenes (Gram-positive bacteria) and E. coli, $P$. aeruginosa (Gram-negative bacteria).

\section{Collection of $V$. negundo leaf biomass}

The biomass was collected from a farm land in Batlagundu, Dindigul District, Tamil Nadu, India. A sample of the leaf bearing voucher Specimen No. NA/MADU/ CHEMDDEMKU/021/07/2018-19 was deposited and preserved at the Department of Botany of one of the reputed Institutes, Tamil Nadu, India, and was identified and authenticated by a botanist/taxonomist of the same institute. The biomass was cleaned well in double distilled water, drained, and dried under shade for a week. Later, the dried leaves were powdered using a domestic blender to prepare activated carbon. The photograph of biomass precursor is given in Fig. 1.

Reagents and chemicals used in the investigation are of analytical grade and purchased from Merck Ltd., India. Doubly distilled water was produced from our laboratory.

Preparation of $V$. negundo leaves activated carbon (VNLA C)-carbonization (activation) with $\mathrm{H}_{3} \mathrm{PO}_{4}$

In a typical preparation, $30 \mathrm{~g}$ of the dried biomass powder was impregnated with $\mathrm{H}_{3} \mathrm{PO}_{4}$ solution in water (in the ratio $1: 1(\mathrm{w} / \mathrm{w})$ ) by heating the powderacid mixture at $60{ }^{\circ} \mathrm{C}$ for $48 \mathrm{~h}$ and kept aside for 24 h. The dried lump was pyrolyzed at $350{ }^{\circ} \mathrm{C}$ for $2 \mathrm{~h}$ in

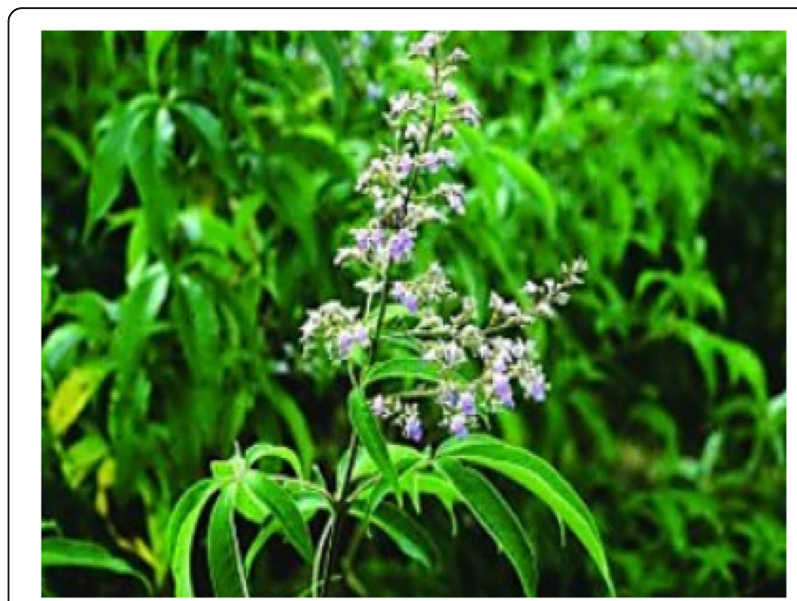

Fig. 1 Photograph of $V$. negundo plant leaves with purple flowers.

a muffle furnace, cooled, powdered using mortar, and finally washed with plenty of hot doubly distilled water to remove the residual acid until the washings are $\mathrm{pH}$ neutral and its conductivity is minimal. $\mathrm{pH}$ nneutrality and low conductivity values of the washings ensure thorough washing of the sample. The mixture is filtered and the resultant black material is thoroughly dried, powdered, and sifted to 250 mesh size. The fine powder is now designated as VNLAC. The sample was stored in an air proof vial for further use. The preparation methodology of VNLAC has been presented in the flow chart (Fig. 2).

\section{Physio-chemical characterization studies}

Physio-chemical characterization studies which include burn-off, elemental analysis, powder X-ray diffractometry (PXRD), Fourier transform infrared spectroscopy, (FTIR), and scanning electron microscopy (SEM) were performed on VNLC sample. Elemental analysis was done on Vario ELIII CHNS/O elemental analyzer. X-ray diffraction pattern of VNLAC was recorded on X'Pert Pro X-ray diffractometer with $\mathrm{CuK}_{\alpha}$ radiation source between 10 and $80^{\circ}$. The morphology of VNLAC was examined with Hitachi S-4700 model scanning electron microscope (SEM). Surfacial functional organic moieties on the surface of the carbon were ascertained with FTIR spectrometer Model \# Nexus 670 from frequency 4000 to $400 \mathrm{~cm}^{-1}$.

\section{Determination of minimal inhibition concentration (MIC)} Minimal inhibition concentration (MIC) is considered as the standard procedure for determining the susceptibility of microorganisms to an antimicrobial. MIC is defined as the lowest concentration of an antibiotic (antibacterial in this study) that will inhibit the visible growth of bacteria after overnight incubation [14]. For the determination of MIC, the method of dilution was followed. In a 


\section{Collection of biomass}

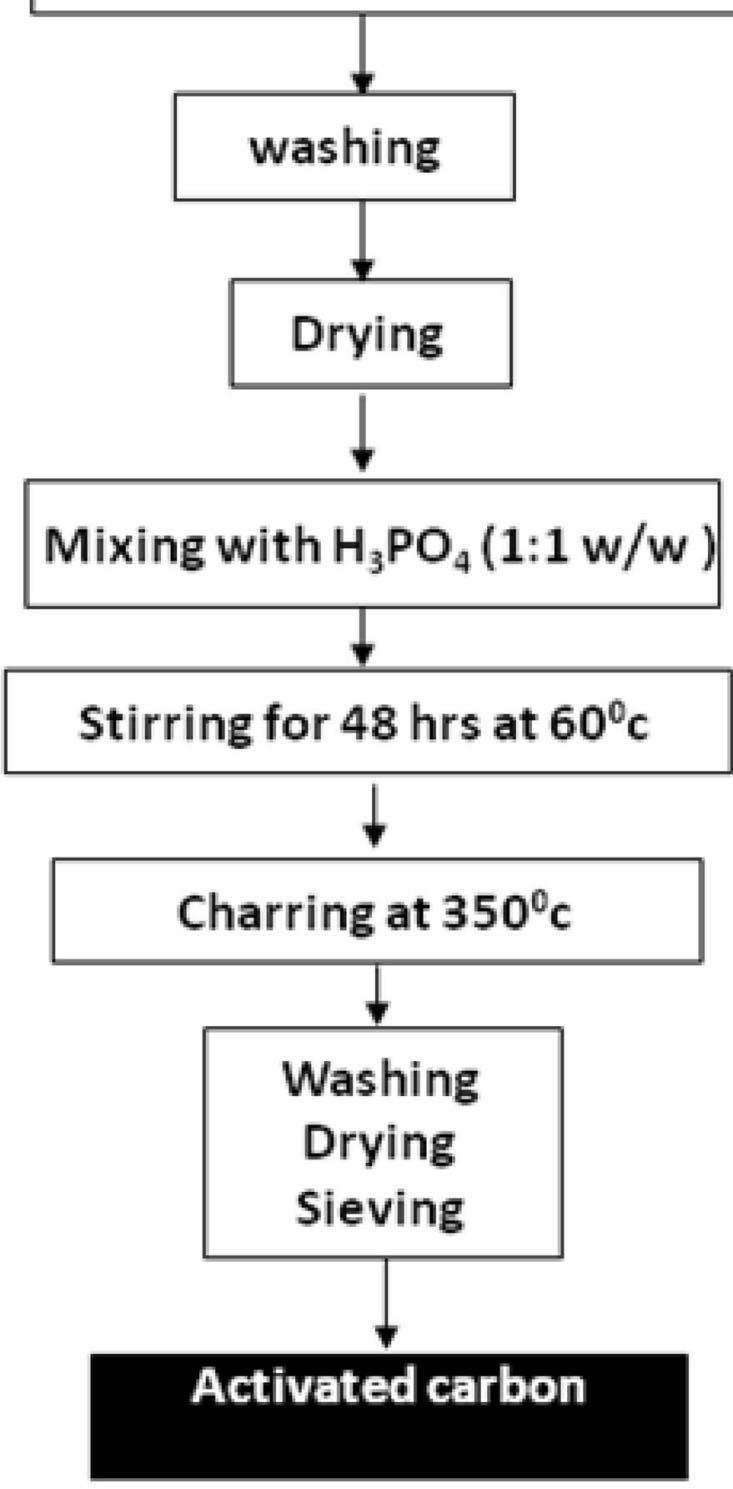

Fig. 2 Flow chart for producing VNLAC

typical procedure, an extract was prepared by dispersing 50 to $90 \mu \mathrm{g}$ of VNLAC in $1 \mathrm{~mL}$ of $5 \%$ DMSO-water mixture with sterile nutrient broth in sterilized glass test tubes by sonicating for $30 \mathrm{~min}$. By means of a standard and sterilized wire loop, purchased from Merck, India, a loop full $(10 \mu \mathrm{L})$ of $E$. coli culture, for example, was inoculated into the test tubes containing $1 \mathrm{~mL}$ of the various concentrations of the VNLAC mixture in the nutrient broth. Similar procedure was followed for the rest of the strains. The test tubes were incubated at 37 ${ }^{\circ} \mathrm{C}$ for 20 to $24 \mathrm{~h}$ and observed for growth or turbidity through unaided eye.
Description on biological activity studies-agar well diffusion method of antimicrobial activity studies Antimicrobial activity of VNLAC was tested by the usual agar well diffusion method. S. aureus (MTCC 96) and $S$. pyogenes (MTCC 442) (representing Gram-positive bacteria) and E. coli (MTCC 443) and P. aeruginosa (MTCC 424) (representing Gram-negative bacteria) were taken for the present study and have been selected on a trial basis only for exploring the efficacy of VNLAC, which could even give information related to formulation or improving the features of VNLAC.

The media, bacterial strains, and other chemicals used in the study are the products of Himedia Laboratories Pvt, Ltd., India. Sterilized Borosil glass wares were used. The glasswares, swabs, and well cutter were sterilized in an autoclave at $120^{\circ} \mathrm{C}$ for $15 \mathrm{~min}$. The bacterial cultures used in the study were regularly sub-cultured and maintained at $4{ }^{\circ} \mathrm{C}$. A sterile cotton swab was used for making lawn cultures of the test pathogens on the readymade solid Muller-Hinton agar petri plates. Required numbers of wells of $6 \mathrm{~mm}$ diameter were punched out of the agar on all the plates by a sterile well borer. Into the wells on the Petri plates, $20 \mu \mathrm{L}$ of the sample extract (prepared by dispersing 100 to $500 \mu \mathrm{g}$ of VNLAC in $1 \mathrm{~mL}$ of $5 \%$ DMSO in water mixture by sonicating for $30 \mathrm{~min}$ ) was added using micropipet. In one well, ciprofloxacin $(30 \mu \mathrm{g})$ disk, the standard antibiotic drug was placed using sterilized forceps and in another well, $20 \mu \mathrm{L}$ of $5 \%$ DMSO in water mixture, which is the blank solution was placed. The setup was let as such to diffuse for $2 \mathrm{~h}$. The plates were then incubated at $30{ }^{\circ} \mathrm{C}$ for $24 \mathrm{~h}$. It is a known fact that if the growth of the bacteria was inhibited a clear zone, called the zone of inhibition, around the wells will be observed and measurement of this zone will give an idea of extent of inhibition. Hence, usually diameter of the zone of inhibition is measured and the values are presented in millimeters $(\mathrm{mm})$. Activity of the VNLAC sample against the four pathogens was compared with the standard ciprofloxacin sample. VNLAC is considered to be inactive against a pathogen if the corresponding zone of inhibition value is lesser than $8 \mathrm{~mm}$ or no zone was developed around the wells.

\section{Data analysis}

The zone of inhibition data are presented as a mean of the triplicate measurements \pm standard error of mean (SEM). Statistical Package for Social Sciences (SPSS version 20.0) software was used for the data analysis. The statistical difference of the mean zone of inhibition due to the four pathogens was independently carried out by one-way analysis of variance (ANOVA) at a significant level of $p<0.05$. 


\section{Results}

Activated carbon sample produced from phosphoric acid activation of the leaf biomass of $V$. negundo plant was evaluated by diverse techniques and the noteworthy results are presented in the following sections.

\section{Physico-chemical features of VNLAC Yield and burn-off}

The \% yield of the activated carbon is the ratio of the weight of the activated carbon $(w)$ obtained to that of the dry and powdered biomass $\left(w_{0}\right)$ taken and is given by the following formula:

$$
\text { Yield }(\%)=\left(w / w_{0}\right) \times 100 \%
$$

The burn-off is the weight loss percentage due to the activation step. The yield of VNLAC was calculated as $66 \%$ and burn-off as $34 \%$.

\section{Ultimate elemental (CHNS) analysis}

The VNLAC was subjected to elemental analysis and observed to contain $60.49 \% \mathrm{C}, 9.36 \% \mathrm{~N}, 0.29 \% \mathrm{~S}$, and $6.98 \% \mathrm{H}$. Earlier reports $[15,16]$ about thermally treated carbon samples the remaining element in the carbon material should be $\mathrm{O}$. This result has been presented in Fig. 3.

\section{Phase analysis by powder X-ray diffractometry (PXRD)} XRD pattern of VNLAC is shown in Fig. 4. The broad reflection between $23^{\circ}$ and $30^{\circ}$ indicates (002) diffraction peak, ascribed to the amorphous and low graphitization nature of VNLAC. In addition, the peak indicates the development of microporous carbon, which is mostly amorphous also with non-crystalline features to a higher degree [17]. It is presumed that a large number of disordered single graphene layers and stacked structures of graphene sheets may be present simultaneously in the texture of the carbon powder [18], and the slightly broad

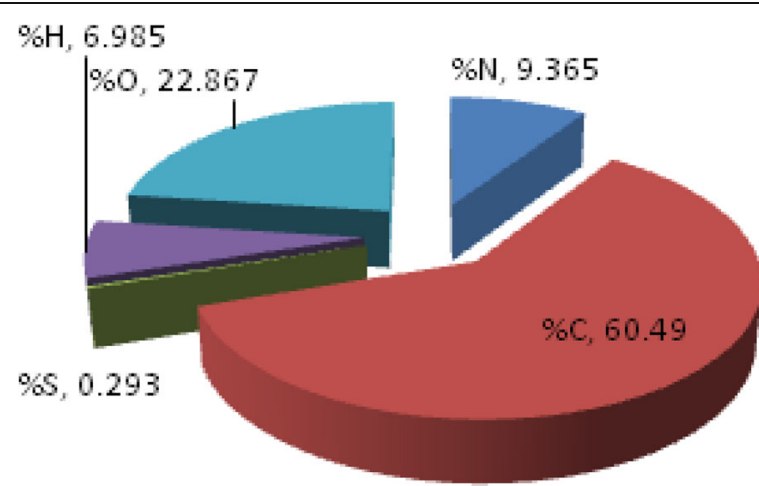

Fig. 3 Ultimate analysis of VNLAC shape also indicates the highly disordered structure in the carbon [19].

The evolution of graphitic structure in VNLAC may be described by the fact that the thermal decomposition of various organic compounds in the biomass results in cleavage of chemical bonds and repolymerization of radicals, further condensing into carbon compounds having characteristic graphitic layers and stacked sheets of graphene [20]. As of now, the authors reserve the study on the correlation between biological activity and the extent of graphitization in the VNLAC.

\section{Morphology by scanning electron microscopy (SEM)}

Scanning electron microscopy (SEM) was employed to identify the particle morphology of the VNLAC powder and Fig. 5 depicts the same.

SEM of VNLAC sample infers that the particles are nearly spherical in shape with lumps distributed sparsely yet compacted together yielding a fine network of all particles. Porosity is also obvious from the SEM. $\mathrm{H}_{3} \mathrm{PO}_{4}$ might have acted aggressively on the cellular features of the precursor biomass resulting in enhanced carbon gasification. It is known that the pores in the chemically activated carbon samples may be reasoned to the paths of the escaping gases (which leave spaces during carbonization) as well as the subsequent removal of unreacted activating chemical by water washing. It has to be stressed that morphology of any biomass-derived carbon samples depends on the activation conditions.

\section{Fourier transform infrared (FTIR) vibrational studies}

In addition to various physical features studied above, the activity of the carbon sample depends also on the chemical structure of the functional groups present at the carbon surface. Hence, knowledge on the surface functional groups gives an insight to the functionality and also the reactivity of the activated carbon. So FTIR data was collected for qualitative chemical information on the surface organic functional groups that are present in VNLAC sample and has been presented in Fig. 6 and data in Table 1.

It is well documented that plant contains phytochemicals like flavonoids, tannins, saponin, glycosides, terpenoids, steroids, quinines, amino acids, and proteins which are responsible for certain physio-chemico as well as biological properties. But during carbonization or pyrolysis of the biomass, these chemicals would tend to decompose and gets converted into various organic functional moieties which decorate the surface of the AC as evidenced from FTIR studies. As a result, FTIR spectrum of VNLAC is also complex due to the presence of many organic functional groups on the carbon surface. The spectrum obtained for VNLAC shows a characteristic signature around $3700 \mathrm{~cm}^{-1}$ which is endorsed 


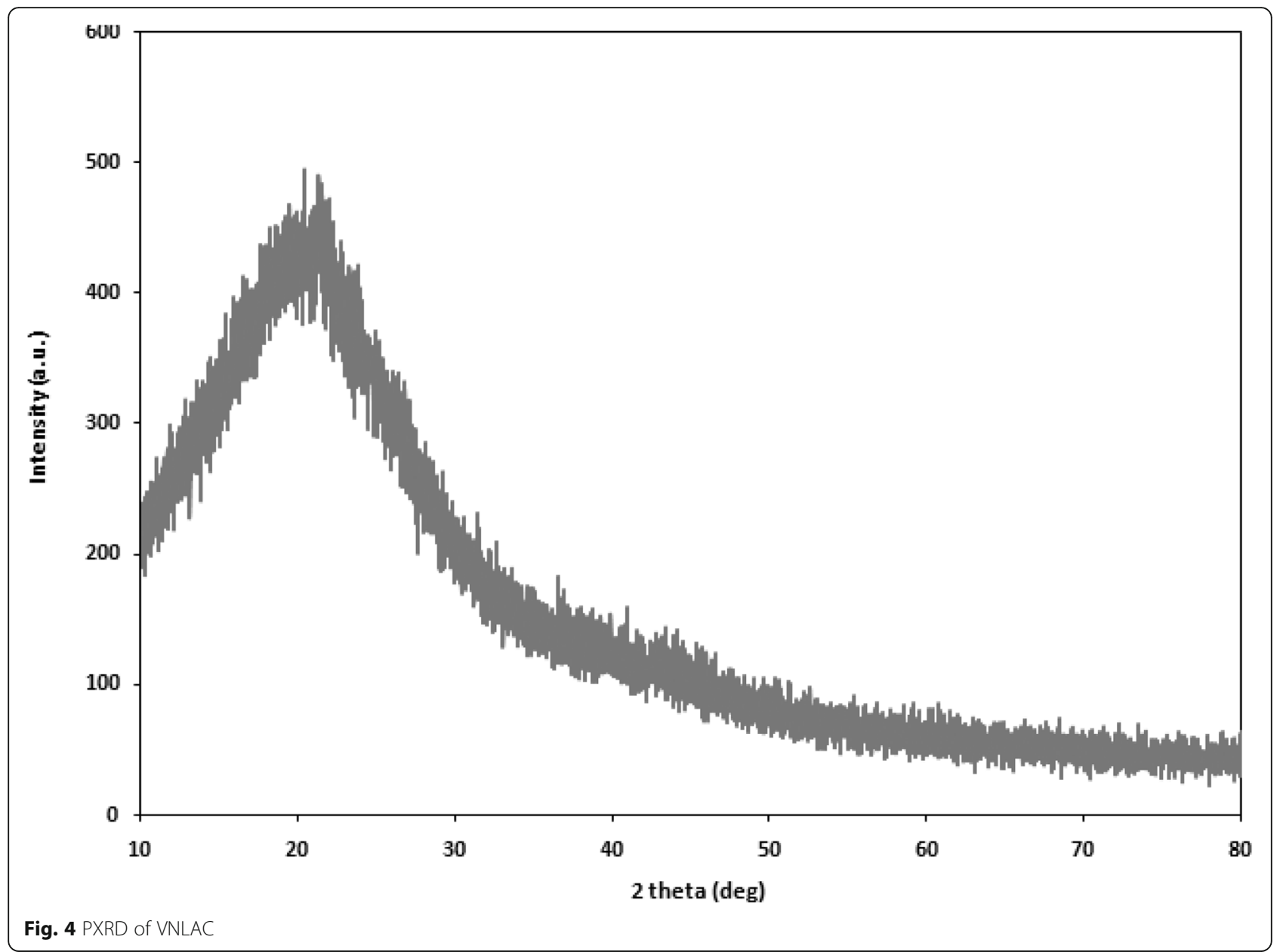

to free $\mathrm{O}-\mathrm{H}$ groups and the peak observed around $3500-3300 \mathrm{~cm}^{-1}$ is due to the NH stretching of amino group [21]. A peak around $2260-2220 \mathrm{~cm}^{-1}$ might be due to the $-\mathrm{C} \equiv \mathrm{N}$ stretching [21] and the IR signature at $1720 \mathrm{~cm}^{-1}$ could be assigned to $\mathrm{C}=\mathrm{O}$ stretching of carbonyl groups [22]. The peaks around $1650-1580 \mathrm{~cm}^{-1}$ are due to the $\mathrm{NH}$ bending or $\mathrm{O}-\mathrm{H}$ bending vibrations of absorbed water with some carboxyl groups [23]. The carboxyl groups are presumed to provide excellent dispersivity [24]. Peak at $1627 \mathrm{~cm}^{-1}$ could be due to the $\mathrm{C}=$ $\mathrm{C}$ ring skeletal stretching of aromatic carbons [25] and IR signature at $1460 \mathrm{~cm}^{-1}$ could be assigned to $\mathrm{C}-\mathrm{H}$ in plane bending vibration of allylic carbon [26]. The band around $1370 \mathrm{~cm}^{-1}$ is due to $\mathrm{C}-\mathrm{H}$ stretching vibration of gem dimethyl group. The band evidenced around 1360 $\mathrm{cm}^{-1}$ is for $\mathrm{S}=\mathrm{O}$ in sulphoxide group [27]. Peak at 1150 $\mathrm{cm}^{-1}$ shows $\mathrm{C}-\mathrm{O}$ stretching vibration of alcohol and $1260,1210 \mathrm{~cm}^{-1}$ represents the $\mathrm{C}-\mathrm{O}-\mathrm{C}$ stretching vibration of ether [28]. A band registered from 700 to 600 $\mathrm{cm}^{-1}$ has been due to $\mathrm{C}-\mathrm{H}$ out of plane bending [22].

Thus $\mathrm{O}, \mathrm{H}, \mathrm{N}$, and $\mathrm{S}$ elements do exist on the surface of the VNLAC as amines, sulphoxide, carboxyls, amino, and alcoholic functional groups. These functional groups present in the carbon matrix of VNLAC are presumed to be bonded to the edges of the carbon layers and may govern the surface chemistry of the carbon [29, 30], which in turn may have a say on the bactericidal properties and efficacy. Figure 7 represents a schematic view of the various organic functional groups that are presumed to be on the surface of the activated carbon.

\section{Results of minimal inhibition concentration (MIC)}

It is to be noted that the test tubes containing concentrations of antibiotic or antibacterial that showed no bacterial growth or turbidity after the first $24 \mathrm{~h}$ of incubation showed turbidity after the addition of equal volumes of sterile nutrient broth and further $24 \mathrm{~h}$ of incubation were said to have minimum inhibitory concentration.

\section{Results of antimicrobial activity of VNLAC against pathogens}

The antimicrobial efficacy were studied in different loading levels of VNLAC $(100,200,300,400$, and $500 \mu \mathrm{g} /$ 


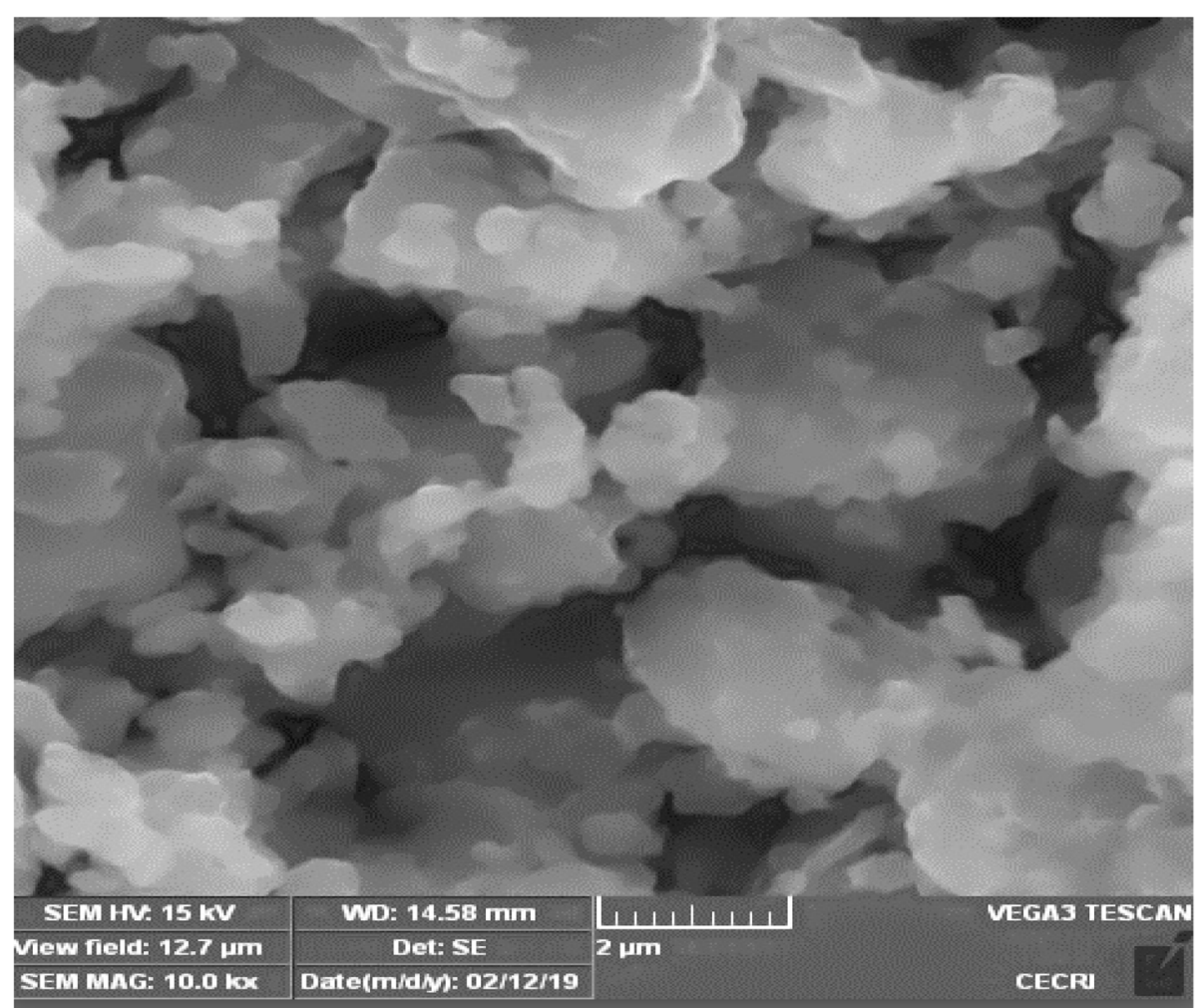

Fig. 5 SEM image of VNLAC

$\mathrm{mL}$ ) in 5\% DMSO against four pathogenic bacterial strains viz., two Gram-positive (S. aureus, S. pyogenes) and two Gram-negative (E. coli, P. aeruginosa). Antimicrobial activity of VNLAC was studied using agar well diffusion method. The study was performed by sterilizing Mueller-Hinton agar media (from Himedia) Petri plates. After solidification, $6 \mathrm{~mm}$ wells were cut on the Mueller-Hinton agar using a sterilized cork borer. The two clinical test bacterial pathogens were separately swabbed onto the surface of the agar petri plates. Wells were impregnated with $20 \mu \mathrm{L}$ of the test samples with

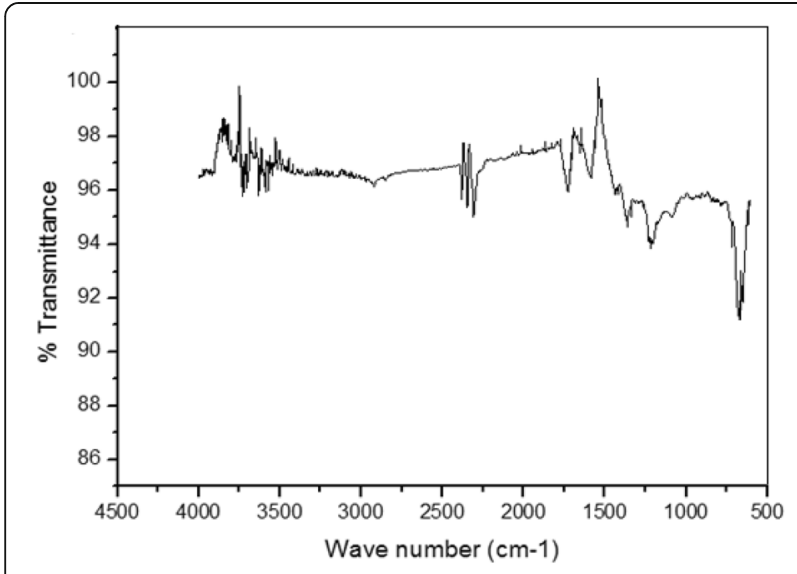

Fig. 6 FTIR spectra of VNLAC different loading from 100 to $500 \mu \mathrm{g}$ of sample/mL of $5 \%$ DMSO. The plates were then incubated at ambient temperature for $30 \mathrm{~min}$ to allow the compound to diffuse into the medium. Finally, the plates were incubated or developed at $30{ }^{\circ} \mathrm{C}$ for $24 \mathrm{~h}$ to get the antibacterial activity evaluated by measuring the zone of inhibition around the wells.

\section{Discussion}

\section{Yield and burn-off}

It is a common understanding that the \% yield of the activated carbon from the raw material would decrease with increase in temperature and so the \% burn-off would tend to increase with increase in temperature. It is worth mentioning that the heat processing of the biomass was carried out in a muffle furnace where there is a free access to air or oxygen; significant amount of carbon content might have been converted as $\mathrm{CO}_{2}$. Nevertheless, increased yields could have been obtained if the sample was heated in an inert atmosphere.

\section{Ultimate elemental (CHNS) analysis}

The result of the elemental analysis has been presented in Fig. 3. The presence of $\mathrm{N}, \mathrm{S}$, and $\mathrm{O}$ shows the existence of various organic functional groups on the surface of the VNLAC sample. The presence of several organic groups containing the hetero elements is also corroborated 
Table 1 FTIR signatures and assignment of FTIR signals of VNLAC

\begin{tabular}{ll}
\hline IR frequency $\left(\mathbf{c m}^{-\mathbf{1}}\right)$ & Assignment \\
\hline $610-700$ & $-\mathrm{C}-\mathrm{H}$ bend, $-\mathrm{C}-\mathrm{S}$ stretching of sulphoxides \\
1150 & $-\mathrm{C}-\mathrm{O}$ stretching vibration of alcohol \\
1260,1211 & $-\mathrm{C}-\mathrm{O}-\mathrm{C}$ stretching vibration of ether \\
1360 & $-\mathrm{S}=\mathrm{O}$ stretching of sulphoxides \\
1370 & $-\mathrm{C}-\mathrm{H}$ stretching vibration of gem dimethyl group \\
1460 & $-\mathrm{C}-\mathrm{H}$ in plane bending vibration of allylic group \\
1627 & $\mathrm{C}=\mathrm{C}$ ring skeletal stretching vibration of aromatic structure \\
$1650-1580$ & $\mathrm{NH}$ bending, O-H bending vibrations of absorbed water with some carboxyl groups \\
1720 & $-\mathrm{C}=\mathrm{O}$ stretching vibration of carbonyl group \\
$2260-2220$ & $-\mathrm{C} \equiv \mathrm{N}$ stretching \\
$3500-3300$ & $-\mathrm{NH}$ stretching of amino group \\
3700 & $\mathrm{OH}$ stretching \\
\hline
\end{tabular}

through vibration spectroscopic studies (FTIR) and is expected to contribute to the overall performance of the VNLAC for the applications for which it is proposed for. The organic groups are rigorously considered in explaining the mechanism of biocidal activity in addition to physical features of the VNLAC powder.

\section{Minimal inhibition concentration}

From Table 2, it can be inferred that all bacterial strains showed turbidity after incubation in nutrient broth with different VNLAC concentrations ranging from 50 through $80 \mu \mathrm{g} / \mathrm{mL}$. After $80 \mu \mathrm{g} / \mathrm{mL}$, no turbidity was observed for all bacterial strains and indicates no further bacterial growth. Hence, $80 \mu \mathrm{g} / \mathrm{mL}$ has been considered as the MIC for all the bacterial strains.

\section{Antimicrobial activity of VNLAC against pathogens}

Each antibacterial assay was performed in triplicate and mean values, which represents the inhibitory effect of
VNLAC \pm SEM is presented in Table 3 . These observations are presented in Fig. 8a (Gram-positive pathogens) and Fig. 8b (Gram-negative pathogens) also.

The antibacterial activity of VNLAC increased linearly with the increase in loading of VNLAC $(\mu \mathrm{g} / \mathrm{mL})$. Compared with the standard ciprofloxacin, the results discovered better antibacterial activity of VNLAC against all the four pathogens studied but Gram-negative types were more active than Gram-positive types. It can be observed from Table 2 that the inhibition zone measured for all the bacteria ranged from 9 to $25 \mathrm{~mm} \pm \mathrm{SEM}$. Also, the zone of inhibition of VNLAC at $500 \mu \mathrm{g} / \mathrm{mL}$ is not significantly different from the value at 400 or $300 \mu \mathrm{g} /$ $\mathrm{mL}$, but it is significantly different at $100 \mu \mathrm{g} / \mathrm{mL}$ against the tested bacteria at $p<0.05$. All the tested bacteria in all concentrations of VNLAC were significantly different from that of the positive control namely Ciprofloxacin (standard $30 \mu \mathrm{g}$ disc) at $p<0.05$ significant level. As expected, the activity was found to be concentration

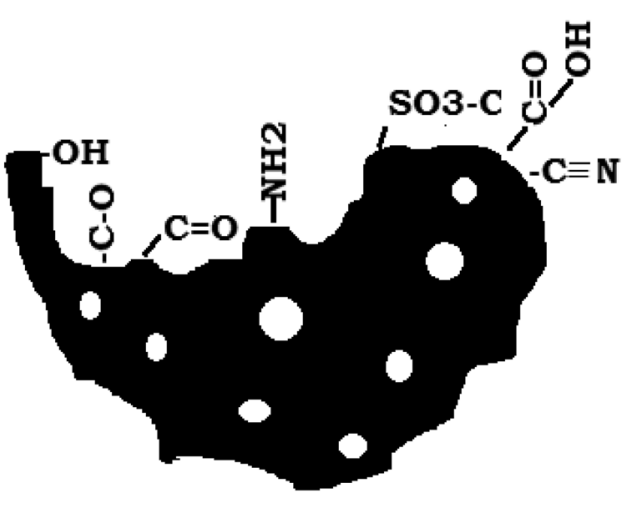

$=$ carbon matrix; $\mathbf{L}=$ pores

Fig. 7 Model of various organic functional groups on the surface of the activated carbon. 
Table 2 Inhibition of bacterial strains using different concentrations of VNLAC in broth after $24 \mathrm{~h}$ of incubation at 37 ${ }^{\circ} \mathrm{C}$

\begin{tabular}{llllll}
\hline $\begin{array}{l}\text { Bacterial } \\
\text { strains } \\
\text { tested }\end{array}$ & $\begin{array}{l}\text { Turbidity in broth } \\
\text { Conc. of VNLAC } \\
(\boldsymbol{\mu g} / \mathrm{mL})\end{array}$ & & & & \\
\cline { 2 - 6 } & $\mathbf{5 0}$ & $\mathbf{6 0}$ & $\mathbf{7 0}$ & $\mathbf{8 0}$ & $\mathbf{9 0}$ \\
\hline S. pyogenes & + & + & + & + & - \\
S. aureus & + & + & + & + & - \\
E. coli & + & + & + & + & - \\
P. aeruginosa & + & + & + & + & - \\
\hline
\end{tabular}

+ indicates growth; - indicates no growth

dependent, as the zone of inhibition increases as we move from 100 to $500 \mu \mathrm{g} / \mathrm{mL}$, as evidenced from Table 3.

As discussed above, VNLAC is more active against Gram-negative types than Gram-positive types. The difference in the inhibitory action of VNLAC against the Gram-positive types studied may be due to the structure of the cell membrane of the Gram pathogens pathogens, where it may be difficult for the particles of VNLAC to move across or break the cell wall to disintegrate the intercellular components of the pathogenic cells. Obviously, the bacterial growth in the control plates (solvent only) was not hindered at all thereby confirming that VNLAC sample possesses better bactericidal activity.

\section{Probable mechanism of action of activated carbon on microbes}

- Microorganisms may adsorb/adhere to carbon surface through strong Van der Waals forces.

- Carbon particles may cross the cell membrane of the bacteria, penetrates into the cell, interacts with intracellular matters, weakens DNA replication thereby inactivating proteins, and prevents bacteria from undergoing cell division finally leading to cell lysis. As a consequence, bacteria cannot easily develop resistance [31].

- Cell-C aggregates formation may cause damage to the cell membrane of bacteria and then release of their DNA content [31].
- Arias et al. [32] have showed that carbon with surface groups of $-\mathrm{OH}$ and $-\mathrm{COOH}$ indicated improved antimicrobial activity to both Grampositive and Gram-negative bacteria. They have also confirmed that antimicrobial activity is carbon particles shape and size dependent. VNLAC sample is also observed to contain these groups and hence the observed antibacterial activity may be explained.

- Effect of sulphur- and nitrogen-containing groups on the antimicrobial activity leaves an opportunity for further research.

Figure 9 represents the probable broad mechanism of antibacterial activity of VNLAC envisaged from the facts discussed above.

One thrust area of study in combating bacterial infections and diseases is the development of affordable and munificent drugs and the choice of using the available drugs with structural modifications. Although some universal guidelines for the treatment of diseases caused by microbes are accepted everywhere, it seems necessary to search for new antimicrobial agents for reasons such as

1. Infecting microbes becoming resistant to present drugs

2. Some drugs producing side effects

3. The present treatment of immune depressed patients being grossly remains unsatisfactory

It is to be noted that recent knowledge on the mechanism of action of the drugs available and the biochemical mechanisms of resistance against them may be a useful basis for designing new and better drugs to fight bacterial diseases. The knowledge of the mechanism of microbial resistance to a drug could indicate the direction in which search for new products that specially overcome this mechanism. Thus, we hope that the information provided in this research paper proves valuable, stimulates broader concerns, and invigorates further developments in this promising field.

The present research suggests that there is no need of complex activation procedure for the production of phytomass-derived carbon with antibacterial activity.

Table 3 Susceptibility of various pathogens to growth inhibition by VNLAC

\begin{tabular}{llllllll}
\hline $\begin{array}{l}\text { Bacterial } \\
\text { strains } \\
\text { tested }\end{array}$ & \multicolumn{6}{l}{ Mean zone of inhibition \pm SEM (in diameter; in $\mathbf{~ m m})^{\mathbf{a}}$} & \\
\cline { 2 - 7 } & $\mathbf{1 0 0} \boldsymbol{\mu \mathbf { g } / \mathbf { m L }}$ & $\mathbf{2 0 0} \boldsymbol{\mu \mathbf { g } / \mathbf { m L }}$ & $\mathbf{3 0 0} \boldsymbol{\mu \mathbf { g } / \mathbf { m L }}$ & $\mathbf{4 0 0} \boldsymbol{\mu \mathbf { g } / \mathbf { m L }}$ & $\mathbf{5 0 0} \boldsymbol{\mu \mathbf { g } / \mathbf { m L }}$ & Ciprofloxacin (30 $\mathbf{\mu g}$ disc) & Control (5\% DMSO in water) \\
\hline S. pyogenes & $11.08 \pm 0.24$ & $14.05 \pm 0.28$ & $16.00 \pm 0.27$ & $17.00 \pm 0.24$ & $18.00 \pm 0.21$ & $22.04 \pm 0.15$ & No zone \\
S. aureus & $09.13 \pm 0.27$ & $12.10 \pm 0.28$ & $14.07 \pm 0.27$ & $15.02 \pm 0.27$ & $16.00 \pm 0.24$ & $22.00 \pm 0.18$ & No zone \\
E. coli & $14.07 \pm 0.29$ & $17.06 \pm 0.25$ & $20.10 \pm 0.28$ & $23.11 \pm 0.27$ & $25.00 \pm 0.24$ & $28.11 \pm 0.12$ & No zone \\
P. aeruginosa & $13.13 \pm 0.29$ & $17.02 \pm 0.26$ & $21.00 \pm 0.28$ & $22.12 \pm 0.24$ & $23.04 \pm 0.21$ & $26.14 \pm 0.12$ & No zone \\
\hline
\end{tabular}



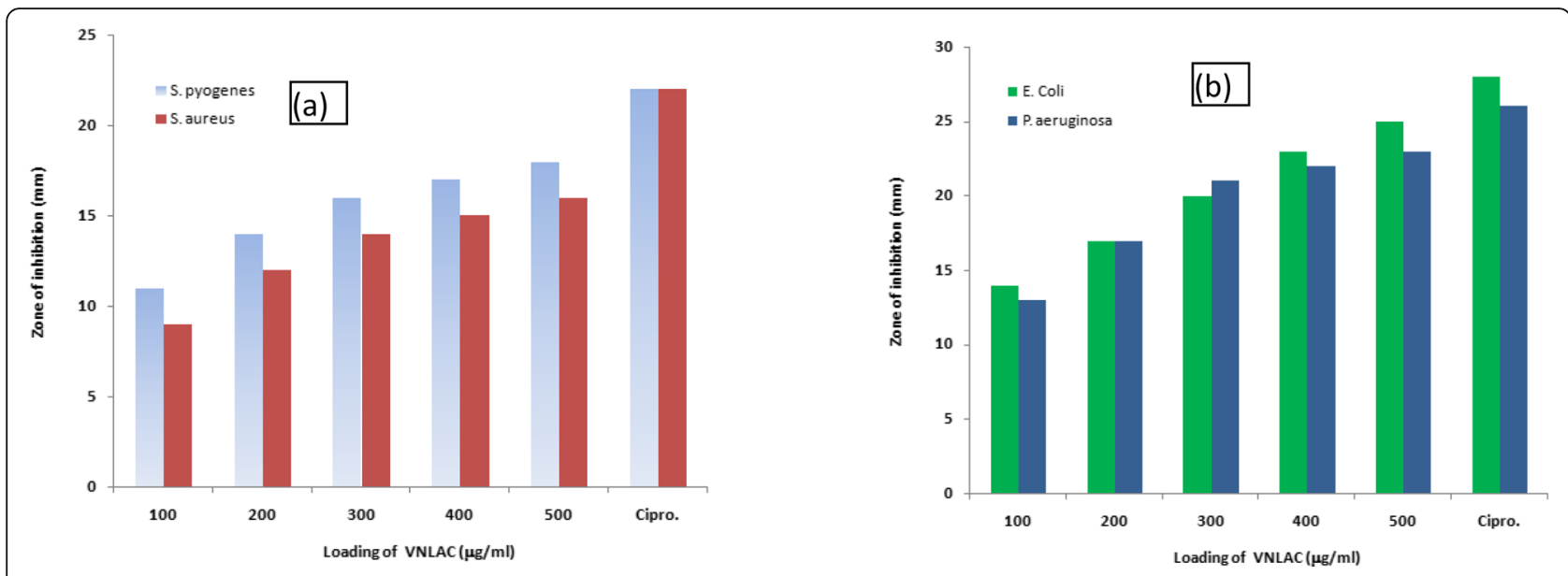

Fig. 8 Antimicrobial activity of VNLAC against Gram-positive pathogens (a) and Gram-negative pathogens (b)

However, means and methods for improving the efficiency of the VNLAC powder (e.g., by functionalizing or surface modification of VNLAC with suitable chemicals) for the complete inhibition of bacterial growth have to be considered immediately. Nevertheless, the present study bestows with an effective way to produce value-added utilization of phytomass discards in the area of pathogenic science and biomedicine and also paves a way towards green environment. Encouraging results realized from the study would certainly attract researchers globally to study various phytomass wastes-derived carbons as novel therapeutic agents which can effectively hinder the growth of various strains of microbes and further for bio imaging and drug delivery as well. Thus, the work represents an essential attempt in producing low-cost carbon powder from $V$. negundo plant phytomass that may possess enormous antimicrobial activity also simultaneously dealing recycling/reuse of environmental wastes. Identification of such agents at low cost as well as the feasibility of producing in bulk would further help reduce the economic burden.

\section{Conclusion}

$\mathrm{H}_{3} \mathrm{PO}_{4}$-activated carbon powder was produced from the green phytomass waste, namely the leaves of $V$. negundo L. plant (VNLAC) and the antibacterial efficacy against four human pathogens was evaluated with a view to adopt as an antibacterial in biomedical field. The source of the carbon is thus natural, zero-cost, and renewable one and the synthesis process is also obviously ecobenign. VNLAC contains hetero elements like N, S, and $\mathrm{O}$ in the form of various functional groups such as amines, carboxyls, sulphoxide, and alcoholic groups on its surface. These organic functional groups are likely to interact with the cell membrane of the pathogens thereby inhibiting their growth and hence play a vital role in the biological activity of VNLAC. This leaves a wider scope for further research on proposing a plausible mechanism for the antibacterial properties of the

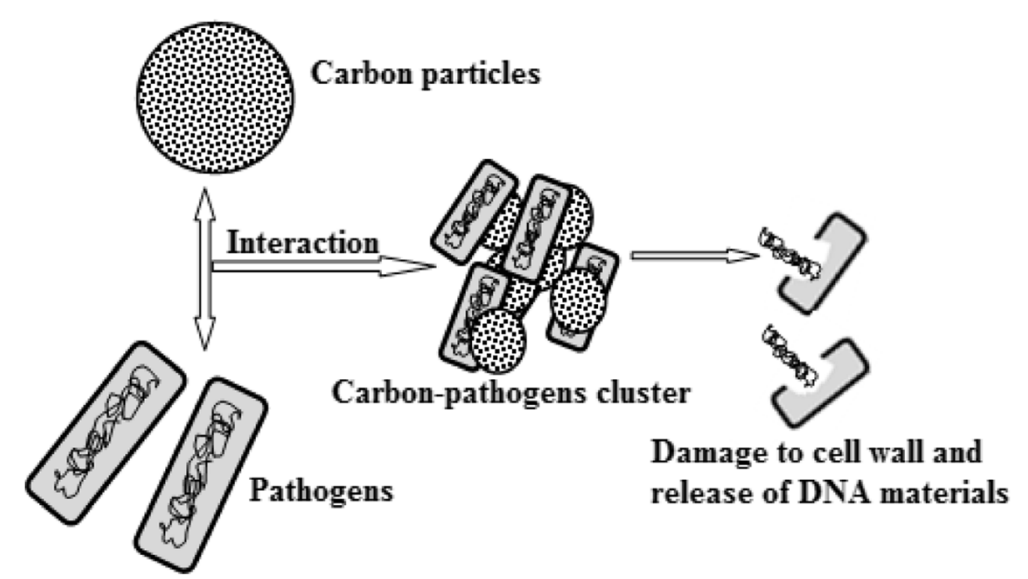

Fig. 9 Representation of probable mechanism of antimicrobial activity of VNLAC 
carbon materials relating the surface organic functional groups.

The present investigation reveals that VNLAC inhibits Gram-negative pathogens efficiently than the Grampositive ones. The difference in inhibition may be due to the complex cell membrane structure. Further, the antibacterial activity increases as we move from low (100 $\mu \mathrm{g} / \mathrm{mL})$ to high $(500 \mu \mathrm{g} / \mathrm{mL})$ concentration of VNLAC. Obviously, VNLAC may be a prospective antibacterial agent for many Gram-negative and Gram-positive bacteria as well. The carbon precursor as well as the process adopted in achieving the carbon are eco-benign, inexpensive, and can be scaled up. The work presented here can be further extended in developing a series of antimicrobial agents of natural origin and this work explores and suggests immense avenues in utilizing our natural resources as therapeutic agents if these are formulated into nanostructured substrates.

\section{Abbreviations \\ S. aureus: Staphyloccus aureus; S. pyogenes: Streptococcus pygogenes; E. coli: Escherichia coli; P. aeruginosa: Pseudomonas aeruginosa; V. negundo: Vitex negundo; $\mathrm{H}_{3} \mathrm{PO}_{4}$ : Phosphoric acid; VNLAC: Vitex negundo leaves derived activated carbon; MIC: Minimal inhibition concentration; PXRD: Powder X-ray diffractometry; FTIR: Fourier transform infrared spectroscopy; SEM: Scanning electron microscopy, standard error of mean; CHNS/O: Carbon, hydrogen, nitrogen, sulphur/oxygen; DMSO: dimethyl sulphoxide; DNA: Deoxyribo nucleic acid}

\section{Acknowledgements}

The authors thank the management of Madurai Kamaraj University, Madurai, for the encouragement to carry out this fundamental research at DDE. We express our gratitude to the experts at various high-end institutes for characterizing our samples. NA thanks Dr. V. Prabhaharan, Venture Labs Madurai, for the antibacterial studies. The authors express sincere gratitude to the esteemed reviewers towards their highly constructive comments and suggestion on the paper.

\section{Plant authentication}

The biomass was collected from a farm land in Batlagundu, Dindigul District, Tamil Nadu, India. A sample of the leaf bearing voucher Specimen No. NA/ MADU/CHEMDDEMKU/021/07/2018-19 was deposited and preserved at the Department of Botany of one of the reputed Institutes, Tamil Nadu, India, and was identified and authenticated by a botanist/taxonomist of the same institute.

\section{Authors' contributions}

NA collected the phytomass samples and followed the experimental procedures and characterized the samples. PK designed experiments, involved in interpretation of the results, and drafted the manuscript. All authors read and approved the final manuscript.

\section{Funding}

Not applicable.

\section{Availability of data and materials}

All data and material are available upon request.

Ethics approval and consent to participate

Not applicable

\section{Consent for publication}

Not applicable.

\section{Competing interests}

The authors do not have conflicts of interest.
Received: 27 August 2020 Accepted: 27 January 2021

Published online: 17 February 2021

\section{References}

1. Solmaz MD, Afsaneh M, Samira J, Khadejeh K, Khosro A (2015) Antimicrobial activity of carbon-based nanoparticles. Adv Pharm Bull 5:19-23. https://doi. org/10.5681/apb.2015.003

2. Pawar SG, Kamble VM (2016) Elemental analysis of anti-allergenic indigenous plants and their possible correlation with therapeutic activity. Int J Pharm Chem Res 8(9):1290-1295

3. Viswanathan AS, Basavaraju R (2010) A review on Vitex negundo L-a medicinally important plant. Eur J Biol Sci 3:30-42

4. Kumar D, Kumar R, Sharda K (2018) Medicinal property of Nirgundi. J Pharmacogn Phytochem 1:2147-2151

5. Matos M, Flomena Barreiro M, Gandini A (2010) Olive stone as a renewable source of biopolyols. Ind Crop Prod 32:7-12. https://doi.org/10.1016/j. indcrop.2010.02.010

6. Humaira P, Raedah A, Nadia H, Sayeed M, Asad UK (2017) Synthesis, characterization and biological evaluation of some novel nitrogen and sulphur containing organometallic heterocycles. Arab J Chem 10(8):10981106. https://doi.org/10.1016/j.arabjc.2015.05.002

7. Yallappa S, Deepthi R, Yashaswini S, Hamsanandini R, Chandraprasad M, Ashok Kumar S, Hegde G (2017) Natural biowaste of groundnut shell derived nano carbons: synthesis, characterization and its in vitro antibacterial activity. Nano Struct Nano Obj 12:84-90. https://doi.org/10. 1016/j.nanoso.2017.09.009

8. Lakshmi SD, Avti PK, Hegde G (2018) Activated carbon nanoparticles from biowaste as new generation antimicrobial agents: a review. Nano Struct Nano Obj 16:306-321. https://doi.org/10.1016/j.nanoso.2018.08.001

9. Sheena V, Sunny K, Soumya J (2013) Antimicrobial activity of carbon nanoparticles isolated from natural sources against pathogenic Gramnegative and Gram-positive bacteria. J Nanosci 2013:1-5. https://doi.org/10. $1155 / 2013 / 457865$

10. Sekaran G, Karthikeyan S, Gupta VK, Boopathy R, Maharaja P (2013) Immobilization of Bacillus sp in mesoporous activated carbon for degradation of sulphonated phenolic compound in wastewater. Mater Sci Eng C Mater Biol Appl 33:735-745. https://doi.org/10.1016/j.msec.2012.10. 026

11. Karthik K, Saraswathy CP (2015) Antimicrobial activity of chemically modified activated carbon of Tribulus terrestris. Res Biotechnol 6(3):42-46

12. Shamsi TN, Parveen R, Afreen S, Azam M, Fatma T, Haque QMR, Fatima S (2014) In-vitro antibacterial and antioxidant activities of sandalwood (Santalum Album). Austin J Biotechnol Bioeng 1(4):1-3

13. Dheeban Shankar P, Basker S, Karthik K, Karthik S (2016) In vitro evaluation of antibacterial efficacy using passiflora foetida activated carbon. Res Pharm 6:1-9. https://doi.org/10.19071/rip.2016.v6.2986

14. Andrews MJ (2001) Determination of minimum inhibitory concentrations. Antimicrob Chemother 48:5-16. https://doi.org/10.1093/jac/48.suppl_1.5

15. Eshkenazi V, Peled E, Burstein LD, Golodnitsky D (2004) XPS analysis of the SEl formed on carbonaceous materials. Solid State Ion 170(1):83-91. https:// doi.org/10.1016/S0167-2738(03)00107-3

16. Lua AC, Guo J (2001) Preparation and characterization of activated carbons from oil-palm stones for gas-phase adsorption. Colloid Surface A 179(2-3): 151-162. https://doi.org/10.1016/S0927-7757(00)00651-8

17. Alcantara R, Ortiz GF, Lavela P, Tirado JL (2006) EPR, NMR, and electrochemical studies of surface-modified carbon microbeads. Chem Mater 18:2293-2301. https://doi.org/10.1021/cm060060p

18. Zhang Y, Zhang F, Li GD, Chen JS (2007) Microporous carbon derived from pinecone hull as anode material for lithium secondary batteries. Mater Lett 61(30):5209-5212. https://doi.org/10.1016/j.matlet.2007.04.032

19. Dahn JR, Sleigh AK, Shi H, Reimers JN, Zhong Q, Way BM (1993) Dependence of the electrochemical intercalation of lithium in carbons on the crystal structure of the carbon. Electrochim Acta 38(9):1179-1191. https://doi.org/10.1016/0013-4686(93)80048-5

20. Kurosaki F, Ishimaru K, Hata T, Bronsveld P, Kobayashi E, Imamura Y (2003) Microstructure of wood charcoal prepared by flash heating. Carbon 41(15): 3057-3062. https://doi.org/10.1016/S0008-6223(03)00434-2

21. Yakout SM, Sharaf El-Deen G (2016) Characterization of activated carbon prepared by phosphoric acid activation of olive stones. Arab J Chem 9: S1155-S1162. https://doi.org/10.1016/j.arabjc.2011.12.002 
22. Pacheco CM, Bustos C, Reyes G, Aguayo MG, Rojas OJ (2018) Characterization of residues from Chilean blueberry bushes: a potential source of cellulose. BioResources 13(4):7345-7359

23. Bello OS (2013) Adsorptive removal of malachite green with activated carbon prepared from oil palm fruit fibre by $\mathrm{KOH}$ activation and CO2 gasification. S Afr J Chem 66:32-41

24. Yang Y, Shi Q, Feng J, Shu X, Feng J (2014) Preparation and antibacterial properties of an activated carbon sphere-quaternary phosphonium salt composite. RSC Adv 4(92):50708-50712. https://doi.org/10.1039/C4RA07282K

25. Ying Liu, Xiaohui Liu, Wenping Dong, Lingli Zhang, Qiang Kong, Weiliang Wang (2017) Efficient Adsorption of Sulfamethazine onto modified activated carbon: A plausible adsorption mechanism. Sci Rep 7(12437):1-12. https:// doi.org/10.1038/s41598- 017-12805-6

26. Al-Qodah Z, Shawabkah R (2009) Production and characterization of granular act Activated carbon from activated sludge. Braz J Chem Eng 26(1): 127-136. https://doi.org/10.1590/S0104-66322009000100012

27. Pierre Ehrburger, Abdelhamid Addoun, Fatima Addoun, Jean-Baptiste Donnet, (1986) Carbonization of coals in the presence of alkaline hydroxides and carbonates: Formation of activated carbons. Fuel 65 (10):1447-1449

28. Terzyk AP (2001) The influence of activated carbon surface chemical composition on the adsorption of acetaminophen (paracetamol) in vitro: part II TG, FTIR, and XPS analysis of carbons and the temperature dependence of adsorption kinetics at the neutral pH. Colloids Surf A Physicochem Eng Aspects 177(1):23-45. https://doi.org/10.1016/ S0927-7757(00)00594-X

29. Subramanian V, Cheng L, Stephan AM, Nahm KS, Thomas S, Wei B (2007) Supercapacitors from activated carbon derived from banana fibers. J Phys Chem C,111(20):7527-7531. https://doi.org/10.1021/jp067009t

30. Wibowo N, Setiyadhi L, Wibowo D, Setiawan J, Ismadji S (2007) Adsorption of benzene and toluene from aqueous solutions onto activated carbon and its acid and heat treated forms: influence of surface chemistry on adsorption. J Hazard Mater 146(1-2):237-242. https://doi.org/10.1016/j. jhazmat.2006.12.011

31. Zhou Y, Kong Y, Kundu S, Cirillo J, Liang H (2012) Antibacterial activities of gold and silver nanoparticles against Escherichia coli and Bacillus sp. J Nano biotechnol 10(19): 19-28

32. Arias $L R$, Yang $L$ (2009) Inactivation of bacterial pathogens by carbon nanotubes in suspensions. Langmuir 25(5):3003-3012. https://doi.org/10. 1021/la802769m

\section{Publisher's Note}

Springer Nature remains neutral with regard to jurisdictional claims in published maps and institutional affiliations.

\section{Submit your manuscript to a SpringerOpen ${ }^{\circ}$ journal and benefit from:}

- Convenient online submission

- Rigorous peer review

- Open access: articles freely available online

- High visibility within the field

- Retaining the copyright to your article

Submit your next manuscript at $\boldsymbol{\nabla}$ springeropen.com 